\title{
CAMA
}

Centre for Applied Macroeconomic Analysis

\section{Animal Spirits, Risk Premia and Monetary Policy at the Zero Lower Bound}

\section{CAMA Working Paper 73/2019 September 2019}

\section{Christian R. Proaño}

Otto-Friedrich-Universität Bamberg

Centre for Applied Macroeconomic Analysis, ANU

\section{Benjamin Lojak}

Otto-Friedrich-Universität Bamberg

\section{Abstract}

In this paper we investigate the risk-related effects of monetary policy in normal times, as well as in periods where the zero lower bound (ZLB) binds, in a stylized macroeconomic model with boundedly rational beliefs. In our model, financial market participants use heuristics to assess the risk premium over the policy rate in accordance to an "implicit Taylor rule" that measures the stance of conventional monetary policy and which serves as an informative instrument during times when the funds rate is constrained by the ZLB. In such a case, conventional monetary policy is exhausted so that the central bank is forced to use unconventional types of policy. We propose alternative monetary policy measures to help the economy out of the liquidity trap which take into account this assumed form of bounded rationality. 


\section{Keywords}

Behavioral Macroeconomics, Monetary Policy, Zero Lower Bound, Bounded Rationality JEL Classification

Address for correspondence:

(E) cama.admin@anu.edu.au

ISSN 2206-0332

The Centre for Applied Macroeconomic Analysis in the Crawford School of Public Policy has been established to build strong links between professional macroeconomists. It provides a forum for quality macroeconomic research and discussion of policy issues between academia, government and the private sector.

The Crawford School of Public Policy is the Australian National University's public policy school, serving and influencing Australia, Asia and the Pacific through advanced policy research, graduate and executive education, and policy impact. 


\title{
Animal Spirits, Risk Premia and Monetary Policy at the Zero Lower Bound
}

\author{
Christian R. Proaño*a,b and Benjamin Lojak ${ }^{\mathrm{a}}$ \\ ${ }^{a}$ Otto-Friedrich-Universität Bamberg \\ ${ }^{\mathrm{b}}$ Centre for Applied Macroeconomic Analysis, Australian National University
}

August 30, 2019

\begin{abstract}
In this paper we investigate the risk-related effects of monetary policy in normal times, as well as in periods where the zero lower bound (ZLB) binds, in a stylized macroeconomic model with boundedly rational beliefs. In our model, financial market participants use heuristics to assess the risk premium over the policy rate in accordance to an "implicit Taylor rule" that measures the stance of conventional monetary policy and which serves as an informative instrument during times when the funds rate is constrained by the ZLB. In such a case, conventional monetary policy is exhausted so that the central bank is forced to use unconventional types of policy. We propose alternative monetary policy measures to help the economy out of the liquidity trap which take into account this assumed form of bounded rationality.
\end{abstract}

Keywords: Behavioral Macroeconomics, Monetary Policy, Zero Lower Bound, Bounded Rationality

*Email: christian.proano@uni-bamberg.de. We would like to thank Michael Roos, Ulrich Fritsche, Lena Dräger, Bernhard Eckwert, Andreas Szczutkowski, Joep Lustenhouwer, Juan Guerra Salas, Tomasz Makarewicz, Emanuel Gasteiger and seminar participants at Bielefeld University, at the First Hamburg Complexity Workshop, the Universidad San Francisco de Quito and the CEF 2018 conference in Milan for helpful comments and suggestions, as well as Berit Rohde for excellent research assistance. 


\section{Introduction}

As it is widely acknowledged, the effectiveness of monetary policy greatly depends on the central bank's credibility among the private sector, as well as on the extent to which it can influence the latter's expectations about the future stance of monetary policy (Woodford, 2003). While this is true in normal times as well as in periods where the zero lower bound (ZLB) on nominal interest rates binds, in the latter this expectations channel of the monetary policy transmission is more important, as conventional short-term interest policy is no longer practicable.

A particular type of expectations management policy which has been implemented by various of the most important central banks around the world is forward-guidance, i.e. the communication to the public about the expected or intended future path of the policy rate. As discussed e.g. by Krugman (1998) and Eggertsson and Woodford (2003), if the economy is in a recession where the ZLB binds, a public commitment by the central bank to keep interest rates low for an extended period of time, namely even after the ZLB is no longer binding, may generate inflationary expectations, thus boosting aggregate demand in the present.

The empirical evidence of the effectiveness of forward-guidance is, however, not particularly encouraging. On the one hand, Gürkaynak et al. (2005) and Campbell et al. (2012) find that Federal Open Market Committee (FOMC) announcements have significant effects on the asset markets using data before the ZLB period following the 2007/2008 financial crisis. On the other hand, Filardo and Hofmann (2014) find that forward-guidance, as implemented by the U.S. Federal Reserve, the Bank of Japan, the European Central Bank and the Bank of England during the latter period seems to have lowered the volatility of near-term expectations of future policy rates, but not the level of the expected interest rates. Further, Kool and Thornton (2015) only provide weak evidence that forward-guidance may have improved the market participants ability to forecast short-term interest rates over short horizons in New Zealand, Norway and Sweden in the post-financial crisis period, and no support for this hypothesis in the United States.

How can the discrepancy between the theoretical power of forward-guidance and its relatively weak empirical evidence be explained? As discussed e.g. by Del Negro et al. (2015) and McKay et al. (2016), this "forward-guidance puzzle" arises from the excess sensitivity of private consumption to interest rate changes implied by the standard Euler consumption 
equation, as well as to the (empirically widely criticized) front-loading character of the New Keynesian Phillips Curve, see also Chung et al. (2014). Indeed, since in standard DSGE models with rational expectations the current output gap depends on the whole path of present and expected future interest rates, and current inflation depends in turn on the whole path of (discounted) output gaps, reductions in policy rates far in the future should have a particularly strong effect on current output and inflation.

By contrast, given the vast empirical evidence supporting different types of bounded rationality (see e.g. Hommes, 2011), recent studies focus on the conduct and the effectiveness of monetary policy at the ZLB under boundedly rational expectations. For Gabaix (2018) the "forward-guidance puzzle" arises from the extreme degree of "forward-lookingness" assumed in standard New Keynesian models. As a remedy, Gabaix (2018) proposes a framework where agents discount future events more as they are more distant in the future. This type of "global cognitive discounting" (Gabaix, 2018) imposes a type of myopia (relative to the rational expectations case) which seems more realistic and which also explains why forwardguidance is not so powerful in reality. Further, Goy et al. (2018) study the effectiveness of forward-guidance when there are two types of agents (adaptive learners and credibility believers) and the central bank's credibility is endogenously determined. Finally, Hommes and Lustenhouwer (2019a) show in a New Keynesian framework with heterogenous and bounded rational expectations that when the ZLB is binding a self-fulfilling deflationary spiral can occur, depending on the central bank's credibility.

Related to these more recent works, the present study explores the functioning and effectiveness of monetary policy in a behavioral macroeconomic framework characterized by endogenously determined beliefs by the economic agents. In contrast to similar frameworks such as Massaro (2013) or Catalano and Di Guilmi (2019) where the switching between alternative beliefs is based on a relative evolutionary fitness measure according to Brock and Hommes (1997), in our model the relative importance of these beliefs is directly related to the agents' assessment of the severity of the ZLB episode. We assume that this severity is assessed by the economic agents through a "policy rate adequacy gap", which we define as the difference between the actual policy rate and the interest rate prescribed by a standard Taylor rule unconstrained by the ZLB. While in normal times these two interest rates are theoretically identical, a potential gap between the two rates emerges at the ZLB, as only the latter can become strictly and significantly negative. Indeed, as illustrated in Figure 1, 


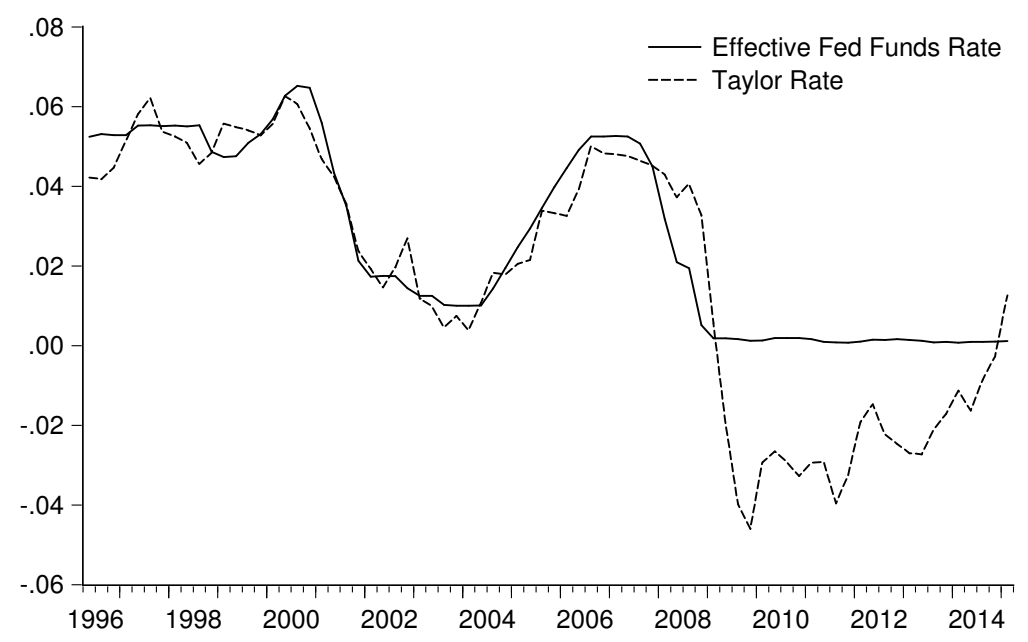

Figure 1: The U.S. Effective Federal Funds Rate, and the Taylor Rate as computed by Bernanke (2015).

the unconstrained Taylor rule (using core PCE inflation and an output gap weight of 1.0 as done by Bernanke, 2015) implied for the period from the year 2009 to the beginning of 2015 that the policy interest rate should have been strongly negative given the macroeconomic conditions summarized by the inflation rate and the output gap. During the same period, the U.S. effective federal funds rate was constrained by the ZLB, and so was conventional monetary policy.

It is reasonable to assume that the larger this ZLB policy rate gap is, the more conventional monetary (interest rate) policy is constrained by the ZLB and the greater is the need for unconventional measures. We assume that economic agents are aware of this relationship, and charge risk premia on financial assets accordingly. Consequently, the risk premium on the risky government bond (the only risky asset in our model economy) is larger the greater the ZLB policy rate gap is. This new mechanism makes the functioning and transmission of monetary policy much more complex than in standard linear rational expectations models. Our model differs thus from the framework studied in Gabaix (2018), for instance, in that our agents' perceptions on the macroeconomy are state-dependent and not, as in his framework, myopic at different degrees. Instead, it allows explicitly for the existence of endogenously determined swings of biased beliefs during ZLB periods that are then responsible for systematic 
increases in the risk premium on the interest rate (relevant for the households' consumption decisions), as well as for the government's financing conditions.

Related work by Reifschneider and Williams (2000), Coibion et al. (2012), Williams (2009) and more recently, Kiley and Roberts (2017) and Bernanke (2017) have also investigated, though from a different perspective, the role of the ZLB policy rate gap for the conduct of monetary policy in a low inflation environment. According to this body of the literature, the central bank should keep track of the accommodation foregone because of the ZLB (measured as the sum of the past ZLB policy rate gaps) and commit to make up some of the foregone accomodation in the near future. This leads the central bank to keep the policy rate low by a longer period than prescribed by a traditional Taylor rule, allowing thus inflation to rise above the long-run target after periods of low inflation, or deflation in the ultimate.

In the following sections we investigate how the existence of these ZLB-related biased beliefs affects the effectiveness of conventional short-term interest rate policy and forwardguidance when the ZLB binds. Alternatively, we investigate the performance of an interest rate rule augmented by a risk premium term, as well as the performance of a varying inflation target rule following Krugman (1998), Blanchard et al. (2010), and Ball (2013), among others, who have argued for an increase of the central bank's inflation target in order to create higher inflation expectations. According to these authors, a permanent higher inflation target may also be helpful to avoid the risk of pushing the economy into a deflationary environment in normal times, as the likelihood of ZLB events may have been underestimated, as shown by Chung et al. (2012). A recent similar contribution by De Grauwe and Ji (2019) illustrates that the economy suffers from "chronic pessimism" that leads to more recessions and deflationary territories when the central bank faces a low (close to zero) inflation target. Consistent with Blanchard et al. (2010), they conclude that central banks should rather increase their inflation target persistently up to a range of $3 \%$ to $4 \%$, thus lowering the probability of negative output gap territories and the risk of hitting the ZLB. By contrast, we consider in the present paper a strategy where the central bank adopts a target of $2 \%$ during normal times and a higher (and endogenously determined) inflation target when the policy rate hits the zero bound. Related to that, this endogenous target policy is assumed to be credible at least to a fraction of households.

The remainder of the paper is as follows. In section 2 we describe our behavioral macroeconomic framework and its basic transmission mechanisms. In section 3 we discuss the dynamics 
of the model under conventional (interest rate) monetary policy and forward-guidance under a binding ZLB. We investigate the performance of alternative monetary strategies which take into account the existence of boundedly rational risk perceptions particularly at the ZLB in section 4. Section 5 draws some concluding remarks from this study.

\section{A Behavioral Macroeconomic Framework}

The nonlinear specification of the agents' beliefs plays the central role in our behavioral macroeconomic framework. Therefore, for the sake of tractability, we set up the remaining behavioral equations in terms of log deviations from the model's steady state (which we consider as exogenous), as done e.g. in Woodford (2013). ${ }^{1}$ Further, we make use of the level expressions to link the main economic variables as well as to define market equilibria. Accordingly, we have

$$
X_{t}=\exp \left(\ln \left(\mathbb{X}_{t}\right)+x_{t}\right)
$$

where $X_{t}$ represents the level of the variable $X_{t}, \mathbb{X}_{t}$ its steady state value (assumed to be constant, i.e. $\left.\mathbb{X}_{t}=\overline{\mathbb{X}}\right)$ and $x_{t}$ the $\log$ deviation of $X_{t}$ from $\mathbb{X}_{t}$.

\subsection{Households' Consumption}

Households' aggregate consumption is described by a simple Euler-type specification

$$
c_{t}=\tilde{E}_{t}\left[c_{t+1}\right]-\sigma^{-1}\left(r_{t}-\tilde{E}_{t}\left[\pi_{t+1}\right]-r^{*}\right)+\epsilon_{t}^{c},
$$

where $c_{t}$ describes households' level of consumption $C_{t}$ as log-deviation from its long-term level $\mathbb{C}, \tilde{E}_{t}\left[c_{t+1}\right]$ represents the subjective expectation of the log-deviation consumption in the next period, $r_{t}$ represents the nominal interest rate relevant for the households' economic decisions (to be defined below), $\tilde{E}_{t} \pi_{t+1}$ the expected inflation rate, $r^{*}$ the equilibrium real interest rate and $\epsilon_{t}^{c}$ a stochastic disturbance which follows an ordinary stationary $\operatorname{AR}(1)$ process.

Along the lines of e.g. De Grauwe (2012) we assume that households switch between two

\footnotetext{
${ }^{1}$ In Woodford's (2013) analysis, this deterministic steady state is characterized by perfect foresight by all agents and monetary and fiscal policies which are consistent with a zero inflation rate. Our model framework could be interpreted along his lines.
} 
different rules-of-thumb concerning their consumption expectations:

$$
\begin{aligned}
& E_{t}^{p}\left[c_{t+1}\right]=\alpha_{c} y_{t-1}, \quad 0<\alpha_{c}<1, \\
& E_{t}^{o}\left[c_{t+1}\right]=0 .
\end{aligned}
$$

According to the first (persistent) expectations rule, deviations from private consumption from its steady state value are linked linearly with the past output gap $y_{t-1}=\ln \left(Y_{t-1} / \mathbb{Y}\right)$ : If $y_{t-1}<0$, private consumption will be expected to be below its long-run value, i.e. $E_{t}^{p}\left[c_{t+1}\right]=\alpha_{c} y_{t-1}<0$, and vice versa. On the contrary, the second rule predicts that private consumption will be at its steady state in the next period, regardless of its current level, see also De Grauwe (2012). As it is standard in this strand of the literature (see e.g. Brock and Hommes, 1997 and Branch and McGough, 2009) the aggregate consumption expectations are given by

$$
\tilde{E}_{t}\left[c_{t+1}\right]=\omega_{t}^{p} E_{t}^{p}\left[c_{t+1}\right]+\left(1-\omega_{t}^{p}\right) E_{t}^{o}\left[c_{t+1}\right]
$$

where $\omega_{t}^{p}$ represents the endogenously determined relative weight of the persistent expectations rule in the aggregate expectations as defined below. ${ }^{2}$

Analogously, agents switch between the following expectational rules-of-thumb concerning future inflation:

$$
\begin{aligned}
& E_{t}^{p}\left[\pi_{t+1}\right]=\pi_{t-1}, \\
& E_{t}^{o}\left[\pi_{t+1}\right]=\pi^{*} .
\end{aligned}
$$

The aggregate inflation expectations are then given by

$$
\begin{aligned}
\tilde{E}_{t}\left[\pi_{t+1}\right] & =\omega_{t}^{p} E_{t}^{p}\left[\pi_{t+1}\right]+\left(1-\omega_{t}^{p}\right) E_{t}^{o}\left[\pi_{t+1}\right], \\
& =\omega_{t}^{p} \pi_{t-1}+\left(1-\omega_{t}^{p}\right) \pi^{*} .
\end{aligned}
$$

\section{$2.2 \quad$ Fiscal Policy}

We assume that the government expenditures are determined by the following simple rule (expressed in log deviations of government spending $G_{t}$ from its long-term counterpart $\mathbb{G}$ ):

$$
g_{t}=-\phi_{g y} y_{t-1}-\phi_{g b}\left(b_{t-1}-\bar{b}\right) \text {. }
$$

\footnotetext{
${ }^{2}$ For the sake of simplicity we assume that the endogenously determined relative weight of the persistent expectations $\omega_{t}^{p}$ is the same both for consumption and inflation expectations.
} 
Accordingly, government spending is a negative function of the past output gap and of the deviation of the past debt-to-GDP ratio $b_{t-1}=B_{t-1} / Y_{t-1}$ from the target $\bar{b}=\mathbb{B} / \mathbb{Y} .^{3}$

Furthermore, the government is assumed to finance its expenditures and outstanding debt by levying taxes and through issuance of new bonds. Under these assumptions, the government's flow budget constraint in nominal terms is described by

$$
P_{t} G_{t}+\left(1+r_{t-1}\right) P_{t-1} B_{t-1}=P_{t} T_{t}+P_{t} B_{t}
$$

The (real) debt-to-GDP ratio is then obtained by dividing the latter equation by output $Y_{t}$ and prices $P_{t}$, hence

$$
b_{t} \equiv \frac{B_{t}}{Y_{t}}=\frac{1+r_{t-1}}{\left(1+\pi_{t}\right)\left(1+\hat{Y}_{t}\right)} b_{t-1}+\frac{G_{t}-T_{t}}{Y_{t}} .
$$

The term $\hat{Y}_{t}$ measures the growth rate of real output and $T_{t}$ is the level of tax revenues which is determined by $T_{t}=\mathbb{T} \exp \left(y_{t}\right)^{\tau_{y}}$, where $\mathbb{T}$ is the long-run tax revenue when the economy operates at its full potential.

Putting all pieces together, the output gap $y_{t}$ can thus be derived by log-linearizing the market clearing identity $Y_{t}=C_{t}+G_{t}$ around the level of potential output $\mathbb{Y}$. Therefore, aggregate demand in terms of deviations around the potential level becomes

$$
y_{t}=\theta_{c} c_{t}+\theta_{g} g_{t}
$$

where $\theta_{c}=\mathbb{C} / \mathbb{Y}$ is the households' exogenous propensity to consume and $\theta_{g}=\mathbb{G} / \mathbb{Y}$ is the government's long-term expenditure-GDP ratio. ${ }^{4}$

\section{$2.3 \quad$ Aggregate Supply}

We follow the standard assumption that firms' production is determined by aggregate demand and that they set their prices as a function of the output gap and their subjective inflation expectations, i.e.

$$
\pi_{t}=\kappa y_{t}+\tilde{E}_{t}\left[\pi_{t+1}\right]+\epsilon_{t}^{\pi} .
$$

\footnotetext{
${ }^{3}$ Mayer and Stähler (2013), using a DSGE framework, analyze also the performance of a balanced budget rule, finding that due to erratic spending behavior, the balance budget rule tends to destabilize the economy and gives rise to sunspot equilibria. Cyclical fluctuations tend to be more pronounced under this regime, as cyclical smoothing does not take place. Such a regime has also a comparatively poor performance in terms of welfare.

${ }^{4}$ We abstract from physical capital accumulation here given the business cycle character of the model. See Galí (2008) for a detailed discussion of the baseline New Keynesian model where physical investment is also abstracted from.
} 
where $\pi_{t}$ denotes price inflation, $\epsilon_{t}^{\pi}$ is a stochastic shock term, $\kappa>0$ being the slope coefficient of traditional Phillips curve and $\tilde{E}_{t}\left[\pi_{t+1}\right]$ is given by eq. (7).

\subsection{Monetary Policy}

\subsubsection{Conventional Taylor Rate Policy}

As it is standard in the literature we assume that conventional (interest rate) monetary policy is determined in normal times (i.e. when the ZLB is not binding) by a standard Taylor rule. Accordingly, the short-term nominal policy rate $i_{t}$ is set equal to the Taylor rule interest rate $i_{t}^{\mathrm{T}}$ which is a function of the gap of (last period's) price inflation from the central bank's inflation target $\pi_{t}^{*}$, and the (last period's) output gap, i.e.

$$
i_{t}=i_{t}^{\mathrm{T}}=\phi_{i} i_{t-1}^{\mathrm{T}}+\left(1-\phi_{i}\right)\left(i^{*}+\phi_{\pi}\left(\pi_{t-1}-\pi^{*}\right)+\phi_{y} y_{t-1}\right)+\varepsilon_{t}^{i}, \quad \forall i_{t} \geq 0,
$$

where $i^{*}$ is the steady-state short-term nominal interest rate, $\phi_{\pi}>1$ the coefficient measuring how the policy responds quantitatively to changes in inflation (as deviations from its target rate), $\phi_{y}>0$ the central bank's responsiveness to output gap fluctuations, $\phi_{i}$ the degree of smoothing in the interest rate setting. By contrast, in times when the ZLB becomes binding, the short-term policy interest rate $i_{t}$ cannot become negative $\left(i_{t} \geq 0\right)$, even though the Taylor rate $i_{t}^{\mathrm{T}}$ may be negative. ${ }^{5}$ This case is not only problematic for the monetary authority since conventional monetary policy becomes totally exhausted; it also implies that the actual interest rate can no longer signal any information concerning the monetary policy's stance.

In our framework, we assume that the difference between the actual policy rate $i_{t}$ and the unconstrained Taylor rate $i_{t}^{\mathrm{T}}$ (what we call the ZLB policy rate gap) is considered by the agents as a measure of undone or required accommodation by conventional monetary policy (see e.g Reifschneider and Williams, 2000 and Kiley and Roberts, 2017), and that this measure drives market sentiments. We discuss this mechanism in subsection 2.5.

\footnotetext{
${ }^{5}$ Note that the concept of the unconstrained Taylor rate differs from the shadow rate concept proposed and estimated by Bullard (2012) and Wu and Xia (2016), which instead measures the stance of monetary policy when taking into account the effects of unconventional policies.
} 


\subsubsection{Risk Premium Augmented Taylor Rule Policy}

Alternatively to the conventional Taylor rule discussed above, we also investigate the performance of the following risk premium augmented Taylor rule:

$$
i_{t}^{\mathrm{T}}=\phi_{i} i_{t-1}^{\mathrm{T}}+\left(1-\phi_{i}\right)\left[i_{o}+\phi_{\pi}\left(\pi_{t-1}-\pi^{*}\right)+\phi_{y} y_{t-1}-\phi_{\zeta} \zeta_{t-1}\right]+\varepsilon_{t}^{i}, \quad \text { with } \phi_{\zeta}>0 .
$$

According to eq. (13), the central bank will decrease the policy rate by an amount of $\phi_{\zeta}$ when the risk premium increases. As we will discuss in subsection 2.5, while the risk premium is affected by macroeconomic conditions in both normal and ZLB periods (see eq. 17), an increasing discrepancy between $i_{t}$ and $i_{t}^{\mathrm{T}}$, which occurs precisely when the ZLB becomes binding, leads to an additional increase in the risk premium. The specified lag structure assumed for the impact of $A_{t}$ on $i_{t}^{\mathrm{T}}$, namely two periods, includes a certain inertia in the policy rate setting, leading thus to a more than usual accommodative interest policy after the ZLB period. ${ }^{6}$

\subsubsection{Endogenous Inflation Target}

There is a broad literature concerning the question of whether an increase of the inflation target may be beneficial in the presence of the ZLB constraint. Some authors like SchmittGrohe and Uribe (2010) and Coibion et al. (2012) argue that a change in the inflation target is not a convenient stabilization tool since it does not necessarily reduce the costs arising from the ZLB. They further claim that low inflation targets, close to zero, reduce the probability of reaching the zero bound on interest rates. Consistently with this line of argumentation, Eggertsson and Woodford (2003) show that raising the inflation target increases the number of periods when the policy rate hits the ZLB, due to a reduction of the natural rate of interest which is conditional for the ZLB to become a binding constraint. In contrast, De Grauwe and Ji (2019) show that for low inflation targets, output gap and inflation appear to be more often negative and thus the risk of hitting the zero bound increases. The authors argue that

\footnotetext{
${ }^{6}$ It should be noted that a similar specification has been proposed e.g. by Cúrdia and Woodford (2010), but was based on a completely different theoretical framework and economic perspective. While these authors set up a medium-scale DSGE Model with financial frictions based on rational expectations, our specification is based on the premise that agents use behavioral rules-of-thumb to form their expectations about future output and inflation developments, and that the ZLB triggers "animal spirits", which rise the risk premium on the interest rate relevant for both households and fiscal authorities.
} 
in such a case the economy is subject to "chronic pessimism" which in turn yields an output gap distribution that is skewed towards the negative values. They further show that inflation targets of $3 \%$ to $4 \%$ (consistent with Blanchard et al., 2010) appear to be optimal, since they lead to a roughly symmetric distribution of the output gap.

While De Grauwe and Ji (2019) study the effects of persistent changes in the inflation target, we consider the following specification of an endogenous inflation target

$$
\pi_{t}^{*}=\left(1-\nu_{\pi^{*}}\right) \pi_{t-1}^{*}+\nu_{\pi^{*}}\left(\pi^{*}+i_{t}-i_{t-1}^{T}\right) .
$$

According to this specification, starting from the steady state where $\pi_{t}^{*}=\pi^{*}$, the inflation target $\pi_{t}^{*}$ would be increased at the ZLB in proportion to $i_{t}-i_{t-1}^{T}$, i.e., by the ZLB policy gap, and would return to $\pi^{*}$ after the ZLB is no longer relevant (with $i_{t}-i_{t-1}^{T}=0$ ) with a velocity determined by $\nu_{\pi^{*}}$. This specification is related to the idea of Chattopadhyay and Daniel (2014) who suggest that the central bank may adopt a time varying inflation target once the ZLB is reached, and a fixed target away from the zero bound. They argue that even though higher inflation targets postpone the date of recovery, the ZLB phase disappears and the exit takes place with higher inflation and output gap. Therefore, their findings are implicitly related to the equilibrium selection discussion of Cochrane (2017) where the policy maker can commit to end the zero bound environment at different magnitudes of the output gap and inflation.

\subsection{Animal Spirits and Risk Premia}

In the following we assume that the private agents are aware of the concept of the Taylor rule and that they explicitly calculate or estimate it. With this information about the "adequate" short-term policy rate they evaluate the "adequacy" of the current stance of conventional monetary policy on the basis of the gap between $i_{t}$ and $i_{t}^{\mathrm{T}}$ (the ZLB policy rate adequacy gap).

The relative populations of agents using the "persistent" and the "steady-state" expectations $E_{t}^{p}[\cdot]$ and $E_{t}^{o}[\cdot]$, respectively, are determined through a binary choice approach (see Brock and Hommes, 1997), namely

$$
\begin{aligned}
\omega_{t}^{p} & =\frac{\exp \left\{\mu\left(i_{t}-i_{t}^{\mathrm{T}}\right)\right\}}{1+\exp \left\{\mu\left(i_{t}-i_{t}^{\mathrm{T}}\right)\right\}} \\
\omega_{t}^{o} & =1-\omega_{t}^{p}
\end{aligned}
$$


where the parameter $\mu \geq 0$ is known as the intensity of choice. According to eq. (15), positive deviations of the actual policy rate from the corresponding implicit Taylor rule rate (which occur solely at the ZLB) lead to an increase in the number of agents with persistent expectations $E_{t}^{p}[\cdot]$ in the market and vice-versa. ${ }^{7}$

A measure for ZLB-related "animal spirits" is

$$
A_{t}=\omega_{t}^{p}-\omega_{t}^{o}, \quad A_{t} \in[-1,1]
$$

This specification possesses the property that $A_{t}$ is bounded between -1 and 1 , where at the steady state the variable takes the value of 0 . A positive value of $A_{t}$ reflects a majority of agents using "persistent" expectations (which are in fact "pessimistic expectations" due to the asymmetric specification of the animal spirits' emergence, see footnote 7).

Further, we assume that the "fundamentals-based" risk premium over the risk-free rate is determined according to

$$
\zeta_{t}=\xi_{a} A_{t-1}-\xi_{y} y_{t-1}+\xi_{b}\left(b_{t-1}-\bar{b}\right)+\xi_{\pi}\left|\tilde{E}_{t}\left[\pi_{t+1}\right]-\pi^{*}\right|+\epsilon_{t}^{\zeta},
$$

where $\xi_{a}, \xi_{y}, \xi_{b}$ and $\xi_{\pi}$ are positive coefficients determining the impact of some macroeconomic variables on the aggregate macroeconomic risk and $\varepsilon_{t}^{\zeta}$ represents a stochastic shock which follows an AR(1)-process. Consistently with the estimates of Adrian et al. (2010), we assume that the output gap is negatively associated with the risk premium on bonds, which can be related to the risk perceptions of the market participants. Further, consistently with the specification of Quint and Rabanal (2014), we also assume that the real debt-to-GDP ratio enters positively in eq. (17) since the more debt is accumulated, the more probable is the debt default and thus the higher the debt default risk. Further, we include in the risk premium equation the absolute deviation of the aggregate inflation expectations from the central bank's target $\pi^{*}$ (as both positive and negative deviations may be considered equally "bad" by the economic agents), as well as the animal spirits variable $A_{t}$ which represents the perception of the majority of market participants concerning the undone accommodation of conventional monetary policy due to the ZLB. In normal times, where the ZLB is not binding, $i_{t}=i_{t}^{\mathrm{T}}$, the "animal spirits" measure $A_{t}$ becomes zero, playing therefore no role in the determination of $\zeta_{t}$, see eq. (17). At the ZLB, on the contrary, $i_{t}=0$, while $i_{t}^{\mathrm{T}}$ may be strongly negative. According to eq. (15) this leads to an increase in the amount of households using the $E_{t}^{p}[\cdot]$

\footnotetext{
${ }^{7}$ Note that $i_{t}-i_{t}^{\mathrm{T}}>0$ only if $i_{t}=0$ and $i_{t}^{\mathrm{T}}<0$, what is likely to occur during an economic recession with $y_{t-1}<0, \pi_{t-1}<0$, or both. If $y_{t-1}<0$, it follows that $E_{t}^{p}\left(c_{t+1}\right)=\alpha_{c} y_{t-1}<0$.
} 
expectations, and thus to an increase of ZLB-related animal spirits which in turn creates an upward bias in the perception of macroeconomic risk.

Finally, the nominal interest rate relevant for the economic decisions of households and of the government is equal to the short-term policy rate plus the perceived risk premium in the financial markets (see e.g. Quint and Rabanal, 2014), which here is simply given by $\zeta_{t}$, i.e.

$$
r_{t}=i_{t}+\zeta_{t}
$$

As we will discuss later, our model will allow for variations in the risky rate during the ZLB partly as a result of the assessment of risk related with the lack of accommodation of conventional monetary policy due to the ZLB, as previously discussed, as well as due to the deterioration of the traditional macroeconomic fundamentals. Our model will thus allow for a varying spread between the risky and the policy rate: a spread that is existent in normal times, and which we assume becomes even more relevant at the ZLB, when conventional interest policy is exhausted and only unconventional policies are available to the monetary authorities.

\section{Short- and Medium-Term Model Dynamics}

\subsection{Parametrization}

Since the present framework deviates in various dimensions from standard DSGE models, the choice of the model parameters is not quite straightforward. ${ }^{8}$ However, whenever possible, we use parameters widely accepted in the literature. In particular, we set the long-run trend components of consumption, government expenditures and lump-sum taxes $\mathbb{C}, \mathbb{G}$ and $\mathbb{T}$ such that in the long-run steady state private consumption to GDP ratio equals 0.8 , the government expenditures to GDP ratio 0.2 (implying thus a ratio of private to government consumption of four), and a balanced government budget, as it is standard in the literature, see e.g. Beetsma and Jensen (2005). As the steady state risky rate is equal to zero, the government debt-to-GDP ratio can be arbitrary, so we set it equal to 0.6 , a standard value in the literature and also a value given by the European Maastricht Criteria.

The real interest rate elasticity of consumption demand (more precisely, the log-linear approximation around its steady state level) determined by $\sigma$ has been estimated independently

\footnotetext{
${ }^{8}$ Additionally, an estimation of the present model seems quite problematic because of the limited availability of ZLB periods.
} 
Table 1: Baseline Parameterization

\begin{tabular}{lcr}
\hline \hline Parameter & Symbol & Value \\
\hline Interest rate elasticity of consumption & $\sigma$ & 2.00 \\
Output gap elasticity of cyclical government expenditures & $\phi_{g y}$ & 0.50 \\
Government debt elasticity of cyclical government expenditures & $\phi_{g b}$ & 0.10 \\
Output gap elasticity of cyclical tax revenues & $\tau_{y}$ & 0.20 \\
Output gap elasticity of price inflation & $\kappa$ & 0.15 \\
Interest rate smoothing parameter & $\phi_{i}$ & 0.20 \\
Inflation gap coefficient in interest rule & $\phi_{\pi}$ & 1.50 \\
Output gap coefficient in interest rule & $\phi_{y}$ & 0.50 \\
Long-term nominal interest rate & $i_{o}$ & 0.02 \\
Central bank's inflation target & $\pi^{\star}$ & 0.02 \\
Share of steady state consumption on output $\mathbb{C} / \mathbb{Y}$ & $\theta_{c}$ & 0.80 \\
Share of steady state government expenditures on output $\mathbb{G} / \mathbb{Y}$ & $\theta_{g}$ & 0.20 \\
Share of steady state taxes on output & $\mathbb{T} / \mathbb{Y}$ & 0.20 \\
Target Debt-to-GDP ratio & $\bar{b}$ & 0.60 \\
Degree of persistence of extrapolative consumption expectations & $\alpha_{c}$ & 0.90 \\
Intensity of choice parameter & $\mu$ & 10.0 \\
Animal spirits herding parameter in the risk premium & $\xi_{a}$ & 0.10 \\
Output gap coefficient in the market's risk perceptions & $\xi_{y}$ & 0.05 \\
Government debt coefficient in the market's risk perceptions & $\xi_{b}$ & 0.015 \\
Absolute inflation gap coefficient in the market's risk expectations & $\xi_{\pi}$ & 0.05 \\
\hline \hline
\end{tabular}

several times by a number of authors. Although these estimates refer to the New Keynesian baseline model including rational expectations, we use the value $\sigma=2.00$ obtained by McCallum and Nelson (1999). Further, we set the slope of the Phillips curve equal to 0.15 based on the empirical estimates of Goodhart and Hofmann (2005). The government sector parameters are set along the lines of the empirical estimates of Galí and Perotti (2003), namely $\phi_{g b}=0.1$, and $\phi_{g y}=0.50$ and $t_{y}=0.2$, implying total cyclical elasticity of the structural budget deficit of the order of magnitude of 0.3, see also Mayer and Stähler (2013). Concerning the monetary policy rule, we assume that $\phi_{\pi}=1.5$ and $\phi_{y}=0.5$ as it is standard in the literature, see e.g. Taylor (1993), as well as $\phi_{i}=0.2$ to allow for some degree of inertia in the policy rate. With respect to the reaction parameters in the risk equation, given the lack of empirical estimates, we set them arbitrarily to $\xi_{a}=0.1, \xi_{y}=0.05$ and $\xi_{\pi}=0.05$. The value of the investors' sensitivity to fluctuations in the debt-to-GDP ratio corresponds 
to $\xi_{b}=0.015$ along the lines of the estimates provided by De Grauwe and Ji (2013, table 1$)$. Table 1 summarizes all these parameter values. Finally, concerning the stochastic shocks to the system, we assume in a standard manner that all of them follow an AR(1)-process (with autoregressive coefficients equal to 0.9 ) and uniform standard deviations equal to 0.002 due to the lack of robust empirical references. ${ }^{9}$

\subsection{Dynamics under Conventional Monetary Policy}

In order to illustrate the functioning of our theoretical framework, we discuss first the dynamic adjustments of the model following a negative aggregate demand shock which lasts for four periods under alternative scenarios. The resulting dynamics are illustrated in Figure 2.

The solid line corresponds to the unrealistic case where the ZLB is not binding (so that the actual nominal interest rate $i_{t}$ can turn negative), and fiscal policy is completely passive regarding business cycle developments $\left(\phi_{g y}=0\right)$. As can be observed, consumption and output decrease due to the negative shock in private consumption, leading to a decrease of inflation and, through the Taylor rule, to a decrease in the nominal interest rate well into the negative domain. The ZLB-related animal spirits do not react, as the ZLB is not binding. However, the risk premium does increase due to the negative developments of the output gap and of price inflation, though not significantly as to reverse the overall negative reaction of the risky rate. Further, the government debt-to-GDP ratio increases initially following the fall in output, leading to a contraction in government expenditures which reduces $b / y$ in the medium-run.

The dashed lined paths illustrate the economy's dynamics when the ZLB binds and fiscal policy is again passive to output gap developments. As it can be observed, consumption, output and inflation remain for a much longer period of time in the negative domain than in the case where the ZLB is not binding. Further, as now ZLB-related spirits are triggered, the increase in the risk premium is much larger, leading over time to an increase in the risky interest rate and to a further depression of consumption, output and price inflation. The pronounced decrease in output leads to a surge in the fiscal debt-to-GDP ratio, which forces the government to reduce expenditures, deepening the economic recession even more.

\footnotetext{
${ }^{9}$ Given the significantly nonlinear structure of the present model, an estimation of the model parameters, even by Bayesian methods, is not a straightforward task, also because the recent ZLB period is very short from an econometric point of view.
} 

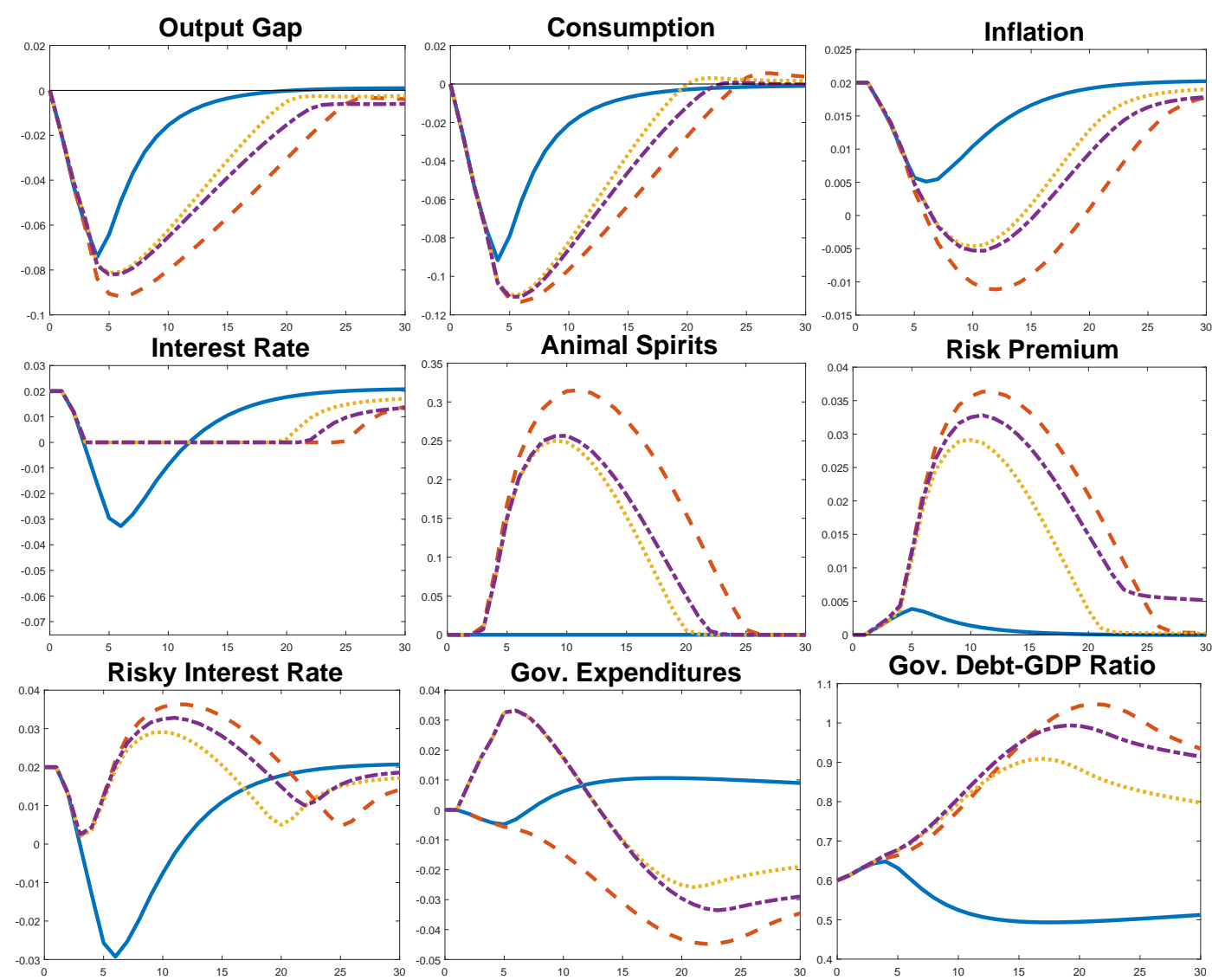

Figure 2: Adjustments after a negative four-period consumption shock $\epsilon_{1}^{c}=-0.02$ under no binding ZLB and passive fiscal policy (solid line), binding ZLB and passive fiscal policy (dashed line), binding ZLB, active fiscal policy and no Debt/GDP ratio in risk premium (dotted line) and binding ZLB, active fiscal policy and Debt/GDP in risk premium (dasheddotted line).

The dotted and dashed lines correspond to the two cases where fiscal policy is reactive to the output gap $\left(\phi_{g y}>0\right)$ and the risk premium does not react to government debt $\left(\zeta_{b}=0\right)$, and where it does $\left(\zeta_{b}>0\right)$. In both cases, consumption, output and inflation return faster to their respective equilibrium levels than in the previous cases when fiscal policy was not countercyclical. Obviously, this leads to a reduction in the severity of the economic recession, and thus of the increase in the risk premium, particularly in the scenario where the latter does not react to fiscal indebtedness. 


\subsection{Dynamics under Forward-Guidance}

As discussed e.g. by Krugman (1998) and Eggertsson and Woodford (2003), a forwardguidance policy seeks to anchor the agents' expectations by means of simple communication to the public. This can be done by the explicit announcement of the future path of short-term interest rates or by the unspecified commitment to the fulfillment of a particular target.

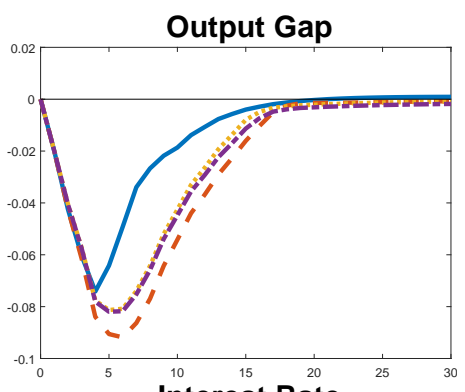

Interest Rate

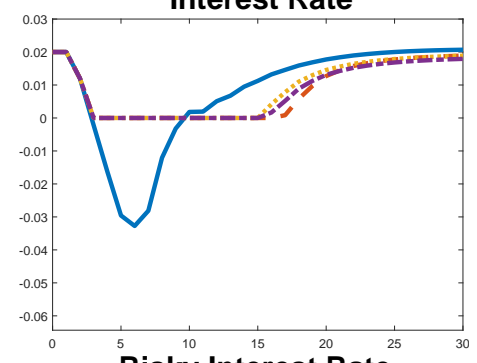

Risky Interest Rate

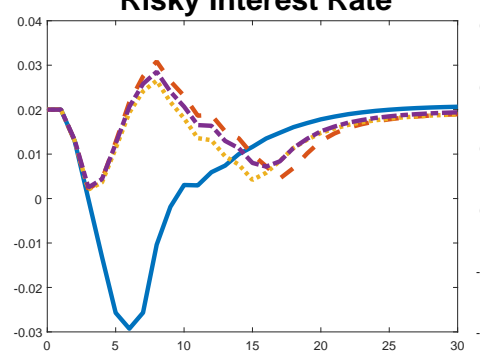

Consumption

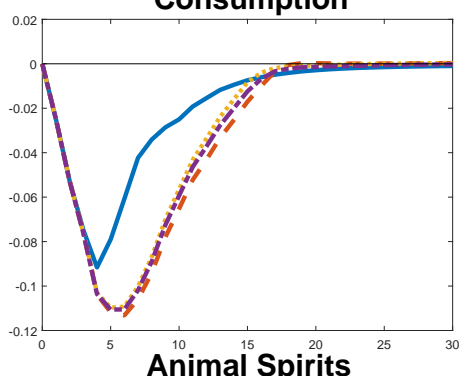

Animal Spirits

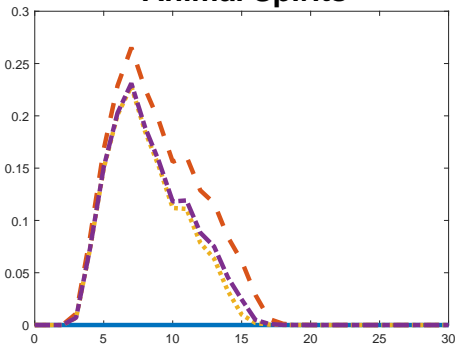

Gov. Expenditures

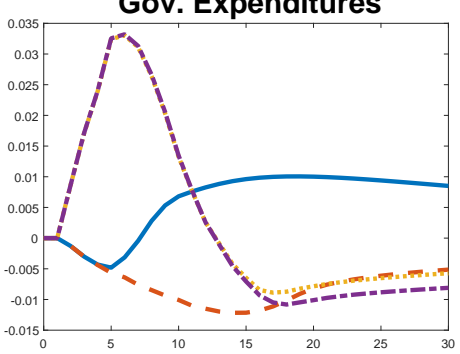

Inflation

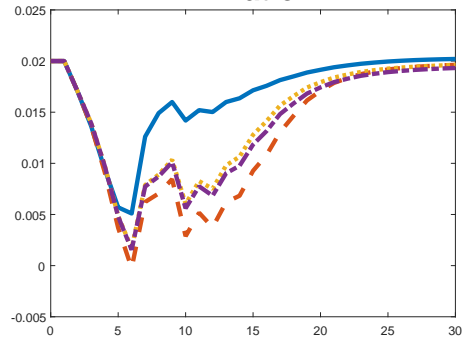

Risk Premium

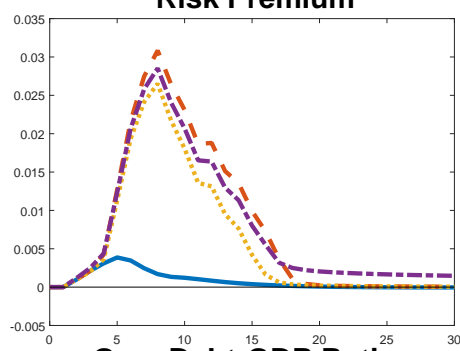

Gov. Debt-GDP Ratio

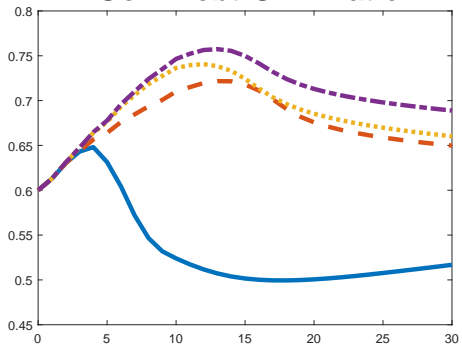

Figure 3: Adjustments after a negative four-period consumption shock $\epsilon_{1}^{c}=-0.02$ under no binding ZLB and passive fiscal policy (solid line), binding ZLB and passive fiscal policy (dashed line), binding ZLB, active fiscal policy and no Debt/GDP ratio in risk premium (dotted line) and binding ZLB, active fiscal policy and Debt/GDP in risk premium (dasheddotted line).

We illustrate in Figure 3 the dynamics of the economy in our model following a central bank announcement of the enforcement of an inflation rate consistent with its target at $t=8,9,10$ which is fully believed in by all market participants. This experiment is similar in spirit 
to the analysis of Arifovic et al. (2018), where, in a nonlinear New Keynesian model with learning, the rational expectations solution is communicated to a fraction of agents, reshaping thus the aggregate inflation expectations in the economy. Specifically, this implies that the sentiment mechanism described by eq. (14) is temporarily cancelled off, so that aggregate expected inflation is temporarily equal to $\pi^{*}$, see also eq. (7).

As this figure illustrates, the central bank can achieve, through the anchoring of inflation expectations - and thus the nonlinear disruption of the model dynamics for three periods - an improvement in the macroeconomic conditions and a reduction in the extent and duration of the economic slump. The macroeconomic mechanism behind this result is the following: by managing to anchor the inflation expectations at $\pi^{*}=0.02$, the decrease of actual inflation following the reduction in macroeconomic activity is not only stopped, but it in fact increases to about 0.015 . This development increases production and consumption, bringing the shortterm nominal interest rate faster back to a positive level. This in turn reduces the risk premium charged in the financial markets, what is also beneficial for the public finances.

It should be noted that this outcome relies on the unlikely assumption that the central bank's announcement is immediately and fully believed by all economic agents. If the central bank's credibility among the public is endogenous and agents have heterogenous expectations, as investigated e.g. by Goy et al. (2018), forward-guidance may be less efficient and take longer to bring the economy away from the ZLB.

\section{The Performance of Conventional and Unconventional Monetary Poli- cies under a binding ZLB}

Now we turn to the analysis of monetary policy rules which take into account the possibility of ZLB-related animal spirits and their feedback in the macroeconomy. More specifically, we consider two alternatives: the modification of the Taylor rule by the inclusion of a risk premium term (which becomes particularly relevant in ZLB periods due to the animal spirits), and the endogenization of the inflation target as a function of a measure of the ZLB.

\subsection{Standard Taylor Rule}

Table 2 summarizes the simulated moments resulting from a Monte Carlo simulation of 1000 times 1000 periods for the main variables assuming that in each period the economy is hit 
by demand, cost-push, risk premium and monetary policy shocks under the implementation of the standard Taylor rule given by eq.(12).

Table 2: Simulated Moments under Conventional Interest Policy, Percent Values.

\begin{tabular}{rcccc}
\hline \hline Variable & Mean & Std.Dev. & Skewness & Kurtosis \\
\hline Output (NOZLB, $\left.\phi_{g y}=0, \xi_{b}=0\right)$ & -0.105 & 0.589 & -0.025 & 2.926 \\
$\left(\mathrm{ZLB}, \phi_{g y}=0, \xi_{b}=0\right)$ & -0.131 & 0.579 & -0.093 & 2.920 \\
$\left(\mathrm{ZLB}, \phi_{g y}>0, \xi_{b}=0\right)$ & -0.132 & 0.547 & -0.095 & 2.914 \\
$\left(\mathrm{ZLB}, \phi_{g y}>0, \xi_{b}>0\right)$ & -0.188 & 0.570 & -0.127 & 2.929 \\
Inflation (NOZLB, $\left.\phi_{g y}=0, \xi_{b}=0\right)$ & 1.975 & 0.711 & -0.006 & 2.896 \\
$\left(\mathrm{ZLB}, \phi_{g y}=0, \xi_{b}=0\right)$ & 1.967 & 0.722 & -0.072 & 3.001 \\
$\left(\mathrm{ZLB}, \phi_{g y}>0, \xi_{b}=0\right)$ & 1.967 & 0.726 & -0.073 & 2.995 \\
$\left(\mathrm{ZLB}, \phi_{g y}>0, \xi_{b}>0\right)$ & 1.945 & 0.731 & -0.085 & 3.020 \\
Risky Rate (NOZLB, $\left.\phi_{g y}=0, \xi_{b}=0\right)$ & 2.053 & 0.010 & 0.001 & 2.911 \\
$\left(\mathrm{ZLB}, \phi_{g y}=0, \xi_{b}=0\right)$ & 2.069 & 0.010 & 0.164 & 2.682 \\
$\left(\mathrm{ZLB}, \phi_{g y}>0, \xi_{b}=0\right)$ & 2.067 & 0.010 & 0.172 & 2.671 \\
$\left(\mathrm{ZLB}, \phi_{g y}>0, \xi_{b}>0\right)$ & 2.099 & 0.010 & 0.201 & 2.688 \\
$\left(\mathrm{ZLB}, \phi_{g y}=0, \xi_{b}=0\right)$ & 63.464 & 0.053 & 0.323 & 2.753 \\
$\left(\mathrm{ZLB}, \phi_{g y}>0, \xi_{b}=0\right)$ & 64.178 & 0.062 & 0.339 & 2.739 \\
$\left(\mathrm{ZLB}, \phi_{g y}>0, \xi_{b}>0\right)$ & 65.959 & 0.076 & 0.467 & 2.779 \\
\hline \hline
\end{tabular}

One can see that the mean of the output gap in the baseline case (where the ZLB is not binding) is significantly higher $(-0.105 \%)$ than in all other cases for the same parameter constellation, illustrating the importance of the ZLB constraint for the long-run dynamics of the economy. Indeed, in the first scenario where the ZLB binds, but no countercyclical fiscal policy $\left(\phi_{g y}=0\right)$ is implemented and the risk premium is independent from the fiscal stance, the mean of the output gap is significantly lower $(-0.132 \%)$ than in the previous case.

It is interesting to note that the implementation of countercyclical fiscal policy, for the given parameter constellation (in particular, for $\xi_{b}=0$ ), does not improve the mean of the long-run output gap significantly relative to the previous case. However, it does reduce the output gap's standard deviation around the long-run mean $(-0.132 \%)$, and having therefore a positive effect, at least in terms of output variability. By contrast, when the risk premium does depend on the government's indebtedness $\left(\xi_{b}>0\right)$, an active countercyclical fiscal policy 
is detrimental for economic activity, as the increase in the government debt-to-GDP ratio leads to an increase in the risky rate, which in turn depresses economic activity, as the lower median output gap ( $-0.188 \%)$ shows. Regarding the skewness of the output gap distribution, the negative values in all four scenarios indicate a left-tailed distribution, assigning a larger probability of severe economic recessions than economic booms. Finally, the kurtosis values of the output gap being in all four scenarios lower than three indicate that the probability mass of the simulated values is located more around the mean than in the case of a normal distribution. In this context, the fact that the lowest kurtosis value is the one corresponding to the scenario with an active countercyclical fiscal policy could be interpreted as indicative for a successful macroeconomic stabilization.

These results concerning the output gap are of course intrinsically related with the other model variables. Our Monte Carlo experiment shows that the median of inflation is the lowest, and the risky rate and the debt-to-GDP ratio the highest in the case where the ZLB binds and $\phi_{g y}>0$ and $\xi_{b}>0 .{ }^{10}$

\subsection{Risk Premium Augmented Taylor Rule}

Analogously to Table 2, Table 3 summarizes the simulated moments resulting from Monte Carlo simulations under the assumption of a risk-augmented interest rate rule as specified by eq. (13). For each variable, the first and the second row in Table 3 correspond to the second row and the fourth row in Table 2, respectively, while the third and the fourth rows illustrate the effects of the inclusion of the risk premium term in the interest rate rule under a passive (third row) and a countercyclical fiscal policy (fourth row).

A number of important and interesting results are to be highlighted. Concerning the output gap, our simulations suggest that the inclusion of the risk premium term into the Taylor rule leads to an improvement of the output gap mean relative to the passive and countercyclical fiscal policy scenario, both when the risk premium is and is not reactive to government debt. Interestingly, the scenario with the lowest output gap is the one where fiscal policy is passive (third row), even though the difference with the countercyclical fiscal policy scenario (fourth row) is relatively small. Regarding inflation, the implementation of

\footnotetext{
${ }^{10}$ We computed all these simulations for $\mu=20$ and $\mu=30$ (the intensity of choice parameter in eq.(15)) and found that, as expected, increasing values of $\mu$ enhance the "animal spirits" effects on the macroeconomic dynamics. These results are available upon request.
} 
Table 3: Simulated Moments of Main Model Variables under a Risk Premium Augmented Interest Policy

\begin{tabular}{|c|c|c|c|c|}
\hline Variable & Mean & Std.Dev. & Skewness & Kurtosis \\
\hline Output (ZLB, $\left.\phi_{g y}=0, \xi_{b}=0, \phi_{\xi}=0\right)$ & -0.131 & 0.579 & -0.093 & 2.920 \\
\hline$\left(\mathrm{ZLB}, \phi_{g y}>0, \xi_{b}>0, \phi_{\xi}=0\right)$ & -0.188 & 0.570 & -0.127 & 2.929 \\
\hline$\left(\mathrm{ZLB}, \phi_{g y}=0, \xi_{b}>0, \phi_{\xi}=0.5\right)$ & -0.067 & 0.571 & -0.086 & 2.941 \\
\hline$\left(\mathrm{ZLB}, \phi_{g y}>0, \xi_{b}>0, \phi_{\xi}=0.5\right)$ & -0.069 & 0.541 & -0.089 & 2.933 \\
\hline Inflation $\left(\mathrm{ZLB}, \phi_{g y}=0, \xi_{b}=0, \phi_{\xi}=0\right)$ & 1.967 & 0.722 & -0.072 & 3.001 \\
\hline$\left(\mathrm{ZLB}, \phi_{g y}>0, \xi_{b}>0, \phi_{\xi}=0\right)$ & 1.945 & 0.731 & -0.085 & 3.020 \\
\hline$\left(\mathrm{ZLB}, \phi_{g y}=0, \xi_{b}>0, \phi_{\xi}=0.5\right)$ & 1.985 & 0.721 & -0.076 & 3.004 \\
\hline$\left(\mathrm{ZLB}, \phi_{g y}>0, \xi_{b}>0, \phi_{\xi}=0.5\right)$ & 1.984 & 0.725 & -0.076 & 3.004 \\
\hline Risky Rate $\left(\mathrm{ZLB}, \phi_{g y}=0, \xi_{b}=0, \phi_{\xi}=0\right)$ & 2.069 & 0.010 & 0.164 & 2.682 \\
\hline$\left(\mathrm{ZLB}, \phi_{g y}>0, \xi_{b}>0, \phi_{\xi}=0\right)$ & 2.099 & 0.010 & 0.201 & 2.688 \\
\hline$\left(\mathrm{ZLB}, \phi_{g y}=0, \xi_{b}>0, \phi_{\xi}=0.5\right)$ & 2.042 & 0.010 & 0.167 & 2.667 \\
\hline$\left(\mathrm{ZLB}, \phi_{g y}>0, \xi_{b}>0, \phi_{\xi}=0.5\right)$ & 2.040 & 0.010 & 0.173 & 2.663 \\
\hline Debt/GDP $\left(\mathrm{ZLB}, \phi_{g y}=0, \xi_{b}=0, \phi_{\xi}=0\right)$ & 63.464 & 0.053 & 0.323 & 2.753 \\
\hline$\left(\mathrm{ZLB}, \phi_{g y}>0, \xi_{b}>0, \phi_{\xi}=0\right)$ & 65.959 & 0.076 & 0.467 & 2.779 \\
\hline$\left(\mathrm{ZLB}, \phi_{g y}=0, \xi_{b}>0, \phi_{\xi}=0.5\right)$ & 61.724 & 0.051 & 0.323 & 2.781 \\
\hline$\left(\mathrm{ZLB}, \phi_{g y}>0, \xi_{b}>0, \phi_{\xi}=0.5\right)$ & 62.144 & 0.060 & 0.340 & 2.765 \\
\hline
\end{tabular}

the risk premium augmented interest rate rule under $\phi_{g y}=0$ and under $\phi_{g y}>0$ generates means $1.985 \%$ and $1.984 \%$ closer to the target of $2 \%$ than the standard rules $(1.967 \%$ and $1.945 \%)$, and thus better outcomes with respect to inflation stabilization.

The accommodative policy rate induced by the inclusion of the risk premium term is also associated with lower average risky rates, as well as with lower government indebtedness levels. However, in contrast to the output gap and inflation variables, the simulated risky rate and the debt-to-GDP ratio feature both right-tailed distributions, which highlights the nonlinear structure of the model.

\subsection{Endogenous Inflation Target}

Analogously to Tables 2 and 3, Table 4 reports the simulated moments of the main model variables under the assumption of an endogenous inflation target as specified by eq.(14) and a binding ZLB. As it can be observed therein, for the first case where fiscal policy is 
passive $\left(\phi_{g y}=0\right)$ and the risk premium is not reactive to government indebtedness $\left(\xi_{b}=0\right)$, the central bank pursues a standard interest rate rule $\left(\phi_{\xi}=0\right)$, while the mean of the simulated output gaps is nearly zero $(0.001 \%)$. This rather positive outcome is coupled with a significantly higher inflation rate $(2.351 \%)$ than in all other cases. The implementation of a time-varying inflation target in an environment where the risk premium is not reactive to the government debt-to-GDP ratio is thus indeed stabilizing, but also inflationary, a result supported also by the values of the third and fourth moments of these variables.

Table 4: Simulated Moments of Main Model Variables under an Endogenous Inflation Target

\begin{tabular}{|c|c|c|c|c|}
\hline Variable & Mean & Std.Dev. & Skewness & Kurtosis \\
\hline Output $\left(\mathrm{ZLB}, \phi_{g y}=0, \xi_{b}=0, \phi_{\xi}=0, \nu_{\pi^{*}}=0.5\right)$ & 0.001 & 0.730 & 0.186 & 8.643 \\
\hline$\left(\mathrm{ZLB}, \phi_{g y}>0, \xi_{b}>0, \phi_{\xi}=0, \nu_{\pi^{*}}=0.5\right)$ & -0.262 & 0.610 & -0.179 & 3.457 \\
\hline$\left(\mathrm{ZLB}, \phi_{g y}=0, \xi_{b}>0, \phi_{\xi}=0.5, \nu_{\pi^{*}}=0.5\right)$ & 0.024 & 0.667 & -0.009 & 5.264 \\
\hline$\left(\mathrm{ZLB}, \phi_{g y}>0, \xi_{b}>0, \phi_{\xi}=0.5, \nu_{\pi^{*}}=0.5\right)$ & 0.022 & 0.631 & -0.033 & 5.032 \\
\hline Inflation $\left(\mathrm{ZLB}, \phi_{g y}=0, \xi_{b}=0, \phi_{\xi}=0, \nu_{\pi^{*}}=0.5\right)$ & 2.398 & 0.922 & 1.737 & 11.273 \\
\hline$\left(\mathrm{ZLB}, \phi_{g y}>0, \xi_{b}>0, \phi_{\xi}=0, \nu_{\pi^{*}}=0.5\right)$ & 1.939 & 0.796 & 0.030 & 5.730 \\
\hline$\left(\mathrm{ZLB}, \phi_{g y}=0, \xi_{b}>0, \phi_{\xi}=0.5, \nu_{\pi^{*}}=0.5\right)$ & 2.202 & 0.863 & 0.096 & 7.751 \\
\hline$\left(\mathrm{ZLB}, \phi_{g y}>0, \xi_{b}>0, \phi_{\xi}=0.5, \nu_{\pi^{*}}=0.5\right)$ & 2.202 & 0.862 & 0.096 & 7.415 \\
\hline Risky Rate $\left(\mathrm{ZLB}, \phi_{g y}=0, \xi_{b}=0, \phi_{\xi}=0, \nu_{\pi^{*}}=0.5\right)$ & 2.341 & 0.011 & 0.585 & 4.716 \\
\hline$\left(\mathrm{ZLB}, \phi_{g y}>0, \xi_{b}>0, \phi_{\xi}=0, \nu_{\pi^{*}}=0.5\right)$ & 2.246 & 0.010 & 0.520 & 3.696 \\
\hline$\left(\mathrm{ZLB}, \phi_{g y}=0, \xi_{b}>0, \phi_{\xi}=0.5, \nu_{\pi^{*}}=0.5\right)$ & 2.313 & 0.010 & 0.173 & 3.978 \\
\hline$\left(\mathrm{ZLB}, \phi_{g y}>0, \xi_{b}>0, \phi_{\xi}=0.5, \nu_{\pi^{*}}=0.5\right)$ & 2.312 & 0.010 & 0.173 & 3.754 \\
\hline Debt/GDP $\left(\mathrm{ZLB}, \phi_{g y}=0, \xi_{b}=0, \phi_{\xi}=0, \nu_{\pi^{*}}=0.5\right)$ & 59.468 & 0.070 & -0.337 & 3.591 \\
\hline$\left(\mathrm{ZLB}, \phi_{g y}>0, \xi_{b}>0, \phi_{\xi}=0, \nu_{\pi^{*}}=0.5\right)$ & 66.974 & 0.088 & 0.639 & 3.196 \\
\hline$\left(\mathrm{ZLB}, \phi_{g y}=0, \xi_{b}>0, \phi_{\xi}=0.5, \nu_{\pi^{*}}=0.5\right)$ & 58.745 & 0.062 & 0.266 & 3.151 \\
\hline$\left(\mathrm{ZLB}, \phi_{g y}>0, \xi_{b}>0, \phi_{\xi}=0.5, \nu_{\pi^{*}}=0.5\right)$ & 58.724 & 0.073 & 0.307 & 3.136 \\
\hline
\end{tabular}

The three other cases under consideration are based on the more realistic assumption that the risk premium reacts positively to increases in the government debt-to-GDP ratio. Two main results must be highlighted: First, the policy mix of a countercyclical fiscal policy and monetary policy with a varying inflation target alone is not beneficial for macroeconomic stability, as it yields a negative output gap mean (-0.262\%) and a government debt-to-GDP ratio which is significantly higher $(66.974 \%)$ than in the other cases. The negative effects of a higher risk premium, which result from an active fiscal spending policy and a subsequently 
higher fiscal debt, are not offset by a varying inflation target, so that the overall effect is negative. Second, a monetary policy which is based on a risk premium augmented interest rate rule and a varying inflation target, leads to almost equivalent positive outcomes concerning all model variables, without or with a countercyclical fiscal spending policy. This is indeed important because of two reasons: First, a varying inflation target as specified in eq. (14) does not generate inflation rates significantly above the standard target of $2 \%$, so that the welfare costs of inflation are not necessarily too high, and second, the small effect of an active fiscal policy in the presence of a monetary policy two-instrument rule relativizes the supposedly effectiveness of the former at the ZLB relative to monetary policy.

\section{Concluding Remarks}

The 2007 global financial crisis led the world economy to the brink of a new Great Depression and showed that hitting the ZLB was not only a theoretical possibility, but that it could become a relevant constraint for policy-making in the major industrialized economies.

The subsequent extensive theoretical and empirical research on monetary policy at the ZLB helped to gain a much better understanding of the limits of policy in this situation. Most of the theoretical analysis of the issue was based, however, on the rational expectations paradigm which is predominant in current macroeconomics. However, as discussed e.g. by Del Negro et al. (2015), McKay et al. (2016) and Gabaix (2018), this assumption often leads to to an excess sensitivity of consumption to interest rate changes, and thus to an overestimation of the power of a forward guidance policy. On the other hand, the literature on heterogenous behavioral expectations has not yet been as proliferous, being Goy et al. (2018) and Hommes and Lustenhouwer $(2019 a, 2019 b)$ notable exceptions.

Our simulation analysis unveiled a number of interesting transmission mechanisms and interactions often overlooked in macroeconomic models with rational expectations, and delivered thus important insights for the conduct of monetary policy in the real world. The main results of our analysis can be summarized as follows: First, when the assessment of what we called the "ZLB policy rate gap" plays a role in the beliefs of the public, a destabilizing feedback mechanism is triggered which is likely to increase the risk perceptions of the economic agents, depressing consumption and output and thus prolonging the ZLB episode. In addition, if markets disdain fiscal indebtedness, the implementation of countercyclical fiscal policy may not be beneficial, but instead it may be actually detrimental for macroeconomic 
stability. Second, we found that making the short-term policy rate react negatively to the risk premium in normal times leads to a significant improvement of the output gap, and a better inflation stabilization on average over all simulations.

The most interesting result of our analysis concerns, however, the interaction between two policy mixes: the monetary policy mix of a risk premium augmented monetary policy rule and a varying inflation target, and the fiscal-monetary policy mix. Concerning the former, we found that such a mix is indeed much more beneficial for macroeconomic stabilization than the implementation of only one of the two instruments. Concerning the latter, we found that if such a monetary policy mix is implemented, fiscal policy becomes also much less relevant, even if the ZLB is a probable constraint. 


\section{References}

Adrian, T., Moench, E. and Shin, H. S. (2010), 'Macro risk premium and intermediary balance sheet quantities', IMF Economic Review 58, 179-207.

Arifovic, J., Grimaud, A., Salle, I. and Vermandel, G. (2018), Reshaping inflation expectations at the zero lower bound, Technical report, University of Amsterdam. Paper presented at the First Behavioral Macroeconomics Workshop at the University of Bamberg.

Ball, L. M. (2013), 'The case for four percent inflation', Central Bank Review 13(2), 17-31.

Beetsma, R. M. and Jensen, H. (2005), 'Monetary and fiscal policy interactions in a microfounded model of a monetary union', Journal of International Economics 67, 320-352.

Bernanke, B. (2015), 'The Taylor rule: A benchmark for monetary policy?'. https://www.brookings.edu/blog/ben-bernanke/2015/04/28/the-taylor-rule-abenchmark-for-monetary-policy/.

Bernanke, B. (2017), Monetary policy in a new era. Paper prepared for conference on Rethinking Macroeconomic Policy, Peterson Institute, Washington DC, October 12-13, 2017.

Blanchard, O., Dell'Ariccia, G. and Mauro, P. (2010), 'Rethinking macroeconomic policy', Journal of Money, Credit and Banking 42(s1), 199-215.

Branch, W. A. and McGough, B. (2009), 'A New Keynesian model with heterogeneous expectations', Journal of Economic Dynamics and Control 33(5), 1036-51.

Brock, W. and Hommes, C. (1997), 'A rational route to randomness', Econometrica 65, 1059 $-1095$.

Bullard, J. (2012), Shadow interest rates and the stance of US monetary policy, Presentation at the Center of Finance and Accounting Research Annual Corporate Finance Conference, Washington University in St. Louis.

Campbell, J., Evans, C., Fisher, J. and Justiniano, A. (2012), 'Macroeconomic effects of FOCM forward guidance', Brookings Papers on Economic Activity Spring.

Catalano and Di Guilmi, C. (2019), 'Uncertainty, rationality and complexity in a multisectoral dynamic model: The dynamic stochastic generalized aggregation approach', Journal of Economic Behavior \& Organization 157(C), 117-144. 
Chattopadhyay, S. and Daniel, B. C. (2014), The inflation target at the zero lower bound, MPRA Paper 66096, University Library of Munich, Germany.

Chung, H., Herbst, E. and Kiley, M. T. (2014), Effective monetary policy strategies in New Keynesian models: A re-examination, in J. A. Parker and M. Woodford, eds, 'NBER Macroeconomics Annual', Vol. 29, MIT Press, pp. 289-344.

Chung, H., Laforte, J.-P., Reifschneider, D. and Williams, J. C. (2012), 'Have we underestimated the likelihood and severity of zero lower bound events?', Journal of Money, Credit and Banking 44, 47-82.

Cochrane, J. H. (2017), 'The new-Keynesian liquidity trap', Journal of Monetary Economics 92(47-63), 47-63.

Coibion, O., Gorodnichenko, Y. and Wieland, J. (2012), 'The optimal inflation rate in new keynesian models: Should central banks raise their inflation targets in light of the zero lower bound?', Review of Economic Studies 79(4), 1371-406.

Cúrdia, V. and Woodford, M. (2010), 'Credit spreads and monetary policy', Journal of Money, Credit and Banking 42(s1), 3-35.

De Grauwe, P. (2012), 'Booms and busts in economic activity: A behavioral explanation', Journal of Economic Behavior and Organization 83(3), 484-501.

De Grauwe, P. and Ji, J. (2013), 'Self-fulfilling crises in the eurozone: An empirical test', Journal of International Money and Finance 34, 15-36.

De Grauwe, P. and Ji, Y. (2019), 'Inflation targets and the zero lower bound in a behavioral macroeconomic model', Economica 86(342), 262-299.

Del Negro, M., Giannoni, M. and Patterson, C. (2015), The forward guidance puzzle, Staff Reports 574, Federal Reserve Bank of New York.

Eggertsson, G. B. and Woodford, M. (2003), 'The zero bound on interest rates and optimal monetary policy', Brookings Papers on Economic Activity 34(1), 139-235.

Filardo, A. and Hofmann, B. (2014), 'Forward guidance at the zero lower bound', BIS Quarterly Review pp. 37-53.

Gabaix, X. (2018), A behavioral New Keynesian model. Harvard University, mimeo. 
Galí, J. (2008), Monetary Policy, Inflation and the Business Cycle: An Introduction to the New Keynesian Framework, Princeton University Press, Princeton.

Galí, J. and Perotti, R. (2003), 'Fiscal policy and monetary integration in europe', Economic Policy 18(37), 533-572.

Goodhart, C. and Hofmann, B. (2005), 'The Phillips Curve, the IS curve and monetary transmission: Evidence for the US and the euro area', CESifo Economic Studies 51(4), 757775 .

Goy, G., Hommes, C. and Mavromatis, K. (2018), Forward guidance and the role of central bank credibility under heterogeneous beliefs, Working Paper 614, De Nederlandsche Bank.

Gürkaynak, R., Sack, B. and Swanson, E. (2005), 'The sensitivity of long-term interest raets to economic news: Evidence and implications for macroeconomic models', American Economic Review pp. 425-36.

Hommes, C. (2011), 'The heterogeneous expectations hypothesis: Some evidence from the lab', Journal of Economic Dynamics and Control 35(1), 1-24.

Hommes, C. and Lustenhouwer, J. (2019a), 'Inflation targeting and liquidity traps under endogenous credibility', Journal of Monetary Economics . forthcoming.

Hommes, C. and Lustenhouwer, J. (2019b), 'Managing unanchored, heterogenous expectations and liquidity traps', Journal of Economic Dynamics and Control . forthcoming.

Kiley, M. T. and Roberts, J. M. (2017), 'Monetary policy in a low interest rate world', Brookings Papers on Economic Activity pp. 317-396.

Kool, C. J. and Thornton, D. L. (2015), 'How effective is central bank forward guidance?', Federal Reserve Bank of St. Louis Review Fourth Quarter, 303-322.

Krugman, P. R. (1998), 'It's baaack: Japan's slump and the return of the liquidity trap', Brookings Papers on Economic Activity 29(2), 137-206.

Massaro, D. (2013), 'Heterogenous expectations in monetary DSGE models', Journal of Economic Dynamics and Control 37, 680-692.

Mayer, E. and Stähler, N. (2013), 'The debt brake: business cycle and welfare consequences of Germany's new fiscal policy rule', Empirica 40, 39-74. 
McCallum, B. T. and Nelson, E. (1999), Performance of operational policy rules in an estimated semiclassical structural model, in 'Monetary Policy Rules', NBER Chapters, National Bureau of Economic Research, Inc, pp. 15-56.

McKay, A., Nakamura, E. and Steinsson, J. (2016), 'The power of forward guidance revisited', American Economic Review 106(10).

Quint, D. and Rabanal, P. (2014), 'Monetary and macroprudential policy in an estimated DSGE model of the euro area', International Journal of Central Banking 10(2), 169-236.

Reifschneider, D. and Williams, J. C. (2000), 'Three lessons for monetary policy in a lowinflation era', Journal of Money, Credit and Banking 32(4), 936-66.

Schmitt-Grohe, S. and Uribe, M. (2010), The optimal rate of inflation, in B. M. Friedman and M. Woodford, eds, 'Handbook of Monetary Economics', Vol. 3, Elsevier, chapter 13, pp. $653-722$.

Taylor, J. B. (1993), 'Discretion versus policy rules in practice', Carnegie-Rochester Conference Series on Public policy 39, 195-214.

Williams, J. C. (2009), 'Heeding daedalus: Optimal inflation and the zero lower bound', Brookings Papers on Economic Activity (Fall), 1-37.

Woodford, M. (2003), Interest and Prices: Foundations of a Theory of Monetary Policy, Princeton University Press.

Woodford, M. (2013), 'Macroeconomic analysis without the rational expectations hypothesis', Annual Review of Economics 5, 303-346.

Wu, J. C. and Xia, D. (2016), 'Measuring the macroeconomic impact of monetary policy at the zero lower bound', Journal of Money, Credit and Banking 48(2-3). 